Article - Agriculture, Agribusiness and Biotechnology

\title{
Hydrothermal Pretreatment as a Strategy for the Improvement of Sugarcane Bagasse Saccharification by Fungal Enzyme Blend
}

\author{
Mariana Furtado Granato de Albuquerque ${ }^{1^{*}}$ \\ https://orcid.org/0000-0001-6518-6799
}

Tiago Ferreira Leal ${ }^{2}$

https://orcid.org/0000-0003-2011-3582

Rafaela Inês de Souza Ladeira Ázar ${ }^{2}$ https://orcid.org/0000-0002-8981-7476
Adriane Maria Ferreira Milagres ${ }^{3}$

https://orcid.org/0000-0003-1133-1254

Valéria Monteze Guimarães ${ }^{2}$

https://orcid.org/0000-0002-0735-6144

\author{
Sebastião Tavares de Rezende ${ }^{2}$ \\ https://orcid.org/0000-0002-2968-6304
}

${ }^{1}$ Federal University of Ouro Preto, Biological Science Research Center, Ouro Preto, Minas Gerais, Brazil; ${ }^{2}$ Federal University of Viçosa, Department of Biochemistry and Molecular Biology, Viçosa, Minas Gerais, Brazil; ${ }^{3}$ University of São Paulo, Department of Biotechnology, Lorena, São Paulo, Brazil.

Editor-in-Chief: Alexandre Rasi Aoki

Associate Editor: Paulo Vitor Farago

Received: 2020.07.01; Accepted: 2021.05.27.

*Correspondence: mariana_granato@hotmail.com; Tel: +55-31-36122422 (M.F.G.A.).

\section{HIGHLIGHTS}

- $\quad$ C. cubensis-P. pinophilum enzyme blend resulted in high levels of synergy

- Mild hydrothermal pretreatment reduced the hemicellulases requirement in hydrolysis

- The best results were obtained by the enzymatic blend in H60-SCB saccharification

Abstract: Obtaining low cost lignocellulolytic enzymes and efficient biomass pretreatment are key to increase the competitiveness of second-generation ethanol in comparison with fossil fuels. The enzymatic cocktail produced by the Chrysoporthe cubensis fungus as well as the mixture prepared with the cocktails of the Chrysoporthe cubensis and Penicillium pinophilum fungi have already proven to be efficient for hydrolyzing biomass pretreated with alkali. In this study, they were evaluated in saccharification of sugarcane bagasse pretreated with dilute acid or hot water at $121^{\circ} \mathrm{C}$ using an enzyme loading equal to 8 filter paper units per gram of biomass. The most promising results were obtained from the hydrolysis of biomass pretreated with hot water by the $C$. cubensis- $P$. pinophilum enzymes blend. In this condition, the glucose and xylose production were $25.2 \mathrm{~g} \cdot \mathrm{L}^{-1}$ and $4.6 \mathrm{~g} \cdot \mathrm{L}^{-1}$, respectively, that resulted in the conversion of $68 \%$ of glucan and $23 \%$ of xylan in only 48 hours. This study shows that the hydrothermal pretreatment is a promising alternative to improve the enzymes performance, produced by the fungi $C$. cubensis and $P$. pinophilum, in the sugarcane bagasse hydrolysis without the need of chemical compounds, generally used in the acid and alkali pretreatments. Furthermore, the hydrothermal pretreatment for 60 min allowed all cocktails applied to convert the cellulose efficiently with only $24 \mathrm{~h}$ of saccharification, which contributes to the energy savings employed in the process. 
Keywords: Biomass pretreatment; Enzymatic hydrolysis; Lignocellulose; Chrysoporthe cubensis; Penicillium pinophilum.

\section{INTRODUCTION}

Brazil is the world leader in sugarcane production (646.4 million tons/year) [1], which is used as a feedstock in the production of first generation ethanol. In this process, approximately $260 \mathrm{~kg}$ of bagasse are generated per ton of processed sugarcane, making this material the most promising Brazilian agro-industrial waste to produce second generation ethanol [2]. However, the cellulosic ethanol production demands mastery of complex, still underdeveloped technologies, which have low yields for the conversion of feedstock into bioethanol, negative energy balance and high production costs [3]. The main challenges are related to enzymatic saccharification of lignocellulosic biomass because this material contains hemicellulose and lignin which are both polymers that hinder the action of biocatalysts on cellulose, lowering the efficiency of fermentable sugars production [4].

Thus, prior to enzymatic hydrolysis, lignocellulosic biomass must be submitted to a pretreatment step, to make cellulose more available to the action of cellulases [5-7]. Pretreatment still represents a significant portion of the process cost $[5,8,9]$ and it is necessary to find a technology that is efficient in the partial or total separation of lignocellulosic components, with a low generation of hydrolysis and fermentation inhibitors, low energetic cost, and minimum sugar loss $[9,10]$. The known methods that act mainly on hemicellulose, the second most abundant polysaccharide in the plant cell wall [6], are acid pretreatment, hydrothermal pretreatment, and steam explosion $[6,11]$. The use of diluted sulfuric acid is the most usual technique on the industrial scale to disrupt lignocellulosic biomass [7,11]. However, the physical-chemical methods (hydrothermal and steam explosion) have the advantages of presenting less environmental impacts and generating fewer inhibitors, if compared to chemical pretreatments $[6,12]$.

The hydrolysis process consists of the conversion of polysaccharides into sugar monomers via the action of chemical compounds or biocatalysts such as enzymes [4]. For the latter technology to be efficient, the combined and synergistic action of several types of enzymes is needed $[4,13]$. Technological bottlenecks of enzymatic hydrolysis are related to low rates of cellulose conversion into glucose and high costs of enzyme production [4]. Moreover, since the composition of lignocellulosic biomass is quite diverse, there is an increasing demand for the development of optimized enzymatic cocktails [14]. Bioprospecting of microorganisms that produce lignocellulolytic enzymes, on-site enzyme production, and the combination of enzymatic extracts produced by different microorganisms (blends) are some alternatives to reduce the cost of obtaining of biocatalysts and increase the saccharification velocity and efficiency [5].

The fungus Chrysoporthe cubensis has recently been discovered as a new source of lignocellulolytic enzymes [13] and since then its set of enzymes has been shown to be efficient in the alkali-pretreated sugarcane bagasse hydrolysis $[10,13,15]$. Furthermore, previous work showed that an enzymatic blend from the mixture of the crude extracts of fungi $C$. cubensis and $P$. pinophilum was also able to convert much of the cellulose and hemicellulose present in the alkali-pretreated sugarcane bagasse [16]. Few studies investigated the influence of different pretreatment methods in the hydrolysis efficiency of biomass by the abovementioned enzymatic mixtures. However, the process efficiency is influenced not only by the chemical composition of biomass and the enzymes used in hydrolysis but also by the type and severity of the pretreatment method [10]. Therefore, the effects of mild pretreatments with diluted acid or hot water on sugarcane bagasse saccharification performed with the $C$. cubensis enzymes and $C$. cubensis- $P$. pinophilum enzyme blend were evaluated. The commercial cocktail Multifect ${ }^{\circledR} \mathrm{CL}$ was used for comparison purposes. So, the present study aimed to discover new conditions to allow a better performance of these cocktails produced in laboratory bench level.

\section{MATERIALS AND METHODS}

\section{Carbon Sources}

Sugarcane bagasse (SCB) was provided by Jatiboca Sugar and Ethanol Plant, Urucânia, MG, Brazil. Wheat bran was obtained at a supermarket in Viçosa, MG, Brazil. Elephant grass was collected in the experimental area of the Animal Science Department of the Federal University of Viçosa, MG, Brazil. 


\section{Obtaining and Growing Microorganisms}

Fungi Chrysoporthe cubensis and Penicillium pinophilum were acquired the mycological collection of the Laboratory of Forest Pathology and Laboratory of Biochemical Technology, respectively, both of the Federal University of Viçosa, MG, Brazil. The microorganisms were cultured and grown according to the method described by Visser and coauthors [16]. After the obtainment of enzymes produced by both fungi, a nylon cloth was used to separate solids by filtration, followed by centrifugation at $15,000 \mathrm{~g}$ for 10 minutes. The clarified enzyme extracts of $C$. cubensis (CC) and $P$. pinophilum (PP) were frozen and stored for further enzymatic analysis. The $C$. cubensis- $P$. pinophilum enzyme blend $(\mathrm{BL})$ was obtained by mixing the supernatants of both fungi cultures at the ratio of 50:50 (v/v) because this methodology generated the enzyme cocktail which presented the best results in the study developed by Visser and coauthors [16].

\section{Enzyme Activities, Sinergy and Protein Quantification}

All enzymatic assays were performed in triplicate with sodium acetate buffer $\left(100 \mathrm{mmol} . \mathrm{L}^{-1}, \mathrm{pH} 5\right)$ at $50^{\circ} \mathrm{C}$. Whatman $\mathrm{N}^{\circ} 1$ filter paper $(1 \times 6 \mathrm{~cm}, 50 \mathrm{mg})$ and carboxymethylcellulose $(1.25 \% \mathrm{w} / \mathrm{v})$ were used as substrates to determine FPase and endoglucanase activities, respectively [17]. The total reducing sugars released during these assays were quantified by dinitrosalicylic (DNS) acid method [18] and a standard glucose curve. Xylanase activity was determined according to the method described by Falkoski and coauthors [13], using xylan from beechwood $(1.25 \% \mathrm{w} / \mathrm{v})$ as substrate and the incubation time was $15 \mathrm{~min}$. The products of this enzyme reaction were also quantified by DNS method, with xylose as the standard. The measurement of $\beta$-glucosidase, $\beta$-xylosidase, $\alpha$-mannosidase, $\beta$-galactosidase, $\alpha$-arabinofuranosidase and cellobiohydrolase activities was done using $\rho P N \beta-G l c, \rho N P \beta-X y l, \rho N P \alpha-M a n, \rho N P \beta-G a l, \rho N P \alpha-A r a$ and $\rho N P \beta-C e l$ as substrates, respectively. These enzymatic assays were done as described by Falkoski and coauthors [13], using a reaction time of $15 \mathrm{~min}$. Laccase assay was performed according to Maitan-Alfenas and coauthors [10], using 2,2'-azino-di-(3-ethylbenzthiazoline sulfonic acid) as substrate and a molar extinction coefficient of $3.6 \times 10^{4} \mathrm{~mol} . \mathrm{L}^{-1} . \mathrm{cm}^{-1}$. In the present study, one unit of enzymatic activity (U) was defined as the amount of enzyme able to release $1 \mu \mathrm{mol}$ of equivalent product per minute.

The level of synergy presents in the $B L$ was calculated by comparison between the measured enzymatic activities of this extract and the theoretical activity expected of the same enzyme according to the equations below:

$$
\begin{gathered}
\text { Theoretical enzyme activity }=\frac{\text { Enzyme activity PP }+ \text { Enzyme activity CC }}{2} \\
\text { Sinergy }(\%)=\frac{\text { Enzyme activity } \mathrm{BL} \times 100}{\text { Theoretical enzyme activity }}
\end{gathered}
$$

The Coomassie Blue binding method was applied to determine the protein concentration of all enzyme extracts, using bovine serum albumin (BSA) as the standard [19].

\section{Sugarcane Bagasse Pretreatments and Yield Calculation}

SCB was washed with distilled water to remove dirt and sugars that might already be present. The washed material was dried in an oven at $70^{\circ} \mathrm{C}$, to remove the moisture, until it achieved a constant mass. The first stage of biomass disruption was done by physical pretreatment, in which all the washed and dried SCB was milled (18 mesh). In the second stage, the milled SCB was submitted to acid or hydrothermal pretreatments. The chemical pretreatment was done as described by Maitan-Alfenas and coauthors [10], but the sulfuric acid concentration was $0.5 \%(\mathrm{v} / \mathrm{v})$. The hydrothermal pretreatment was performed using only distilled water, at a solid loading of $10 \%(\mathrm{w} / \mathrm{v})$ in an autoclave at $121^{\circ} \mathrm{C}$, for 20 or 60 minutes.

After pretreatment, a Buchner funnel fitted with filter paper was used to filter the materials. The liquid fractions were used to quantify the inhibitors generated during the different pretreatments while the distilled water was applied to wash the solid fractions. The first wash was performed at room temperature at a ratio of 1:10 (sugarcane bagasse/distilled water) [20] using a Buchner funnel fitted with filter paper. The resulting materials were separated into two parts. One part of the washed solids was dried and sealed in a hermetic vessel to retain moisture, stored at $-20^{\circ} \mathrm{C}$ until its use in saccharification experiments. The other part of the washed solids was applied in a second wash at the same conditions to remove all inhibitors compounds adhered to the pretreated sugarcane bagasse and allow the calculation of the concentration of the inhibitors even present in the different biomasses at the beginning of enzymatic hydrolysis. Considering the dry weight 
of the sugarcane bagasse samples before and after the pretreatment step, the loss mass and yield of the process was calculated according to Equation 3.

$$
\text { Yield }(\%)=\left(\frac{\text { Pretreated-SCB dry weight }(\mathrm{g})}{\text { Raw-SCB dry weight }(\mathrm{g})}\right) \times 100
$$

\section{Quantification of Inhibitors Released from Sugarcane Bagasse Pretreatments}

The liquid fractions resulted from each pretreatment method and the wastewater resulting from each washing step of pretreated bagasse were used to quantify the inhibitors released during the disruption of biomass. The Prussian blue method [21] was applied to analyze phenolic compounds, using gallic acid as the standard. The high-performance liquid chromatography (HPLC) was carried out to determine the concentrations of furans (furfural and hydroxymethylfurfural) and organic acids (levulinic, acetic, and formic acids) using a Shimadzu series 10A chromatograph equipped with an Aminex HPX-87H column $(300 \times 7.8$ $\mathrm{mm}$ ) and refractive index detector. The column was eluted with water at a flow rate of $0.6 \mathrm{~mL} / \mathrm{min}$ and it operated at $65^{\circ} \mathrm{C}[20]$.

\section{Chemical composition and structure analysis of SCB samples}

In order to evaluate the effects of different pretreatments in biomass composition and also allow to calculate the hydrolysis efficiency, a modified Klason lignin method $[15,22]$ was used to determine the chemical composition of the raw, acid- and hydrothermal-pretreated SCB. The values of cellulose, hemicellulose and lignin in the different samples were analyzed using the GraphPad Prisma 6.01 software, performing analysis of variance (ANOVA) followed by Tukey's test at a significance level of $5 \%(\alpha=0.05)$. The standard deviation was also calculated for all assays. To perform the structure analysis, the samples were dried at $60{ }^{\circ} \mathrm{C}$ for 7 days. Then, the dry materials were sputter-coating with gold prior to they be examined and photographed using a Leo 1430VP scanning electron microscope.

\section{Conversion of pretreated SCB into glucose and xylose}

The methodology described by Maitan-Alfenas and coauthors [10] was applied to concentrate the enzyme mixtures produced at the laboratory bench level and it also was adapted to realize the enzymatic hydrolysis experiment. During $48 \mathrm{~h}$, the acid- and hydrothermal-pretreated SCB saccharification were performed in triplicate with $\mathrm{CC}, \mathrm{BL}$ and Multifect ${ }^{\circledR} \mathrm{CL}$ (MCL) using $25 \mathrm{~mL}$ Erlenmeyer flasks with $10 \mathrm{~mL}$ working volume and an enzyme loading of 8 FPase units per gram of biomass. Samples $(0.2 \mathrm{~mL})$ of the reaction medium were taken throughout the experiment to monitor the glucose and xylose production. A Shimadzu series 20A chromatograph, equipped with an Aminex HPX-87P column (300 x $7.8 \mathrm{~mm})$ and refractive index detector, was used for HPLC analysis of products released in the saccharification assays [10]. The efficiency of glucan and xylan conversion were calculated according to Falkoski and coauthors [13].

\section{RESULTS AND DISCUSSION}

Synergy is defined as the interactions that occur between two or more hydrolytic components, producing an effect total greater than the sum of the effects of the individual components [16]. While the PP has advantageous over cellulase content, the CC stood out due to the activities of some hemicellulases. The BL presented the highest activities and high levels of synergy for most enzymes evaluated, except $\alpha$ arabinofuranosidase and laccase (Table 1).

The PP and CC were produced by submersion and solid-state fermentation, respectively, from specific carbon sources for each culture medium. The difference between the fungal growth methodologies probably induced enzymes with distinct properties [23] and when mixed, the extracts complement each other, generating a more complete cocktail. When investigating the enzymatic profile of the 50:50 blend composed of the crude extracts of $C$. cubensis and $P$. pinophilum, Visser and coauthors [16] found a synergistic action between them concerning the FPase (76\%), endoglucanase (50\%) and xylanase (24\%) activities. According to the present work, this blend does not only result in the improvement of the enzymatic activities already described in the literature but also in the synergistic action related to the $\beta$-cellobiohydrolase, $\beta$-glucosidase, $\alpha$-mannosidase, $\beta$-xylosidase and $\beta$-galactosidase activities (Table 1). It contributes to the BL being a complete and efficient cocktail in the biomass hydrolysis. 
Table 1. Enzymatic profiles of crude extracts produced in laboratory bench level and analysis of synergy between them.

\begin{tabular}{|c|c|c|c|c|}
\hline \multirow{2}{*}{ Enzyme } & \multicolumn{3}{|c|}{ Activities (UI.mL-1) } & \multirow{2}{*}{ Synergy Level (\%) } \\
\hline & P. pinophilum & C. cubensis & Blend & \\
\hline FPase & $0.13 \pm 0.01$ & $0.17 \pm 0.00$ & $0.23 \pm 0.01$ & 53 \\
\hline Endoglucanase & $3.75 \pm 0.21$ & $0.73 \pm 0.06$ & $5.60 \pm 0.37$ & 150 \\
\hline$\beta$-cellobiohydrolase & $0.23 \pm 0.01$ & $0.42 \pm 0.02$ & $0.72 \pm 0.03$ & 125 \\
\hline$\beta$-glucosidase & $0.15 \pm 0.00$ & $0.78 \pm 0.04$ & $3.08 \pm 0.19$ & 569 \\
\hline Xylanase & $40.0 \pm 3.76$ & $7.42 \pm 0.51$ & $44.8 \pm 2.93$ & 89 \\
\hline a-mannosidase & n.d. & $0.01 \pm 0.00$ & $0.02 \pm 0.00$ & 300 \\
\hline$\beta$-xylosidase & $0.16 \pm 0.00$ & $0.02 \pm 0.00$ & $0.18 \pm 0.00$ & 100 \\
\hline$\alpha$-arabinofuranosidase & $0.06 \pm 0.00$ & $0.40 \pm 0.02$ & $0.06 \pm 0.00$ & n.d. \\
\hline$\beta$-galactosidase & $0.16 \pm 0.00$ & $0.02 \pm 0.00$ & $0.22 \pm 0.01$ & 144 \\
\hline Laccase & $1.73 \pm 0.00$ & $0.99 \pm 0.00$ & $1.02 \pm 0.00$ & n.d. \\
\hline
\end{tabular}

n.d., not detected

Protein analysis showed that $\mathrm{CC}, \mathrm{BL}$ and MCL presented a protein concentration of $0.536 \pm 0.032$ $\mathrm{mg} \cdot \mathrm{mL}^{-1}, 0.162 \pm 0.002 \mathrm{mg} \cdot \mathrm{mL}^{-1}$ and $65.106 \pm 1.245 \mathrm{mg} \cdot \mathrm{mL}^{-1}$, respectively. Unlike extracts produced at the laboratory bench level, Multifect ${ }^{\circledR} \mathrm{CL}$ is a commercial cocktail with a large amount of solubilized proteins. Therefore, a direct comparison between volumetric activities found in different enzymatic extracts does not allow a fair evaluation [13]. FPase is the standard activity considered to determine the enzyme loading in saccharification processes, which justifies the use of this parameter as a reference to establish a comparative analysis between the different extracts [13]. Therefore, all enzymatic activities analyzed were indexed in relation to FPase activity and the results can be observed in Table 2.

Table 2. Comparative analysis of cellulases and hemicellulases activities present in the cocktails applied in the saccharification experiment. The reported values were obtained by dividing the mean of each enzymatic activity by the mean FPase activity found in each cocktail.

\begin{tabular}{|c|c|c|c|}
\hline \multirow{2}{*}{ Enzyme } & \multicolumn{3}{|c|}{ Units of enzymatic activity / FPase } \\
\hline & C. cubensis & Blend & Multifect ${ }^{\circledR} \mathrm{CL}$ \\
\hline FPase & 1.00 & 1.00 & 1.00 \\
\hline Endoglucanase & 4.29 & 24.3 & 99.52 \\
\hline$\beta$-cellobiohydrolase & 2.47 & 3.13 & 0.15 \\
\hline$\beta$-glucosidase & 4.58 & 13.4 & 0.73 \\
\hline Xylanase & 43.6 & 194.8 & 44.98 \\
\hline a-mannosidase & 0.06 & 0.08 & n.d. \\
\hline$\beta$-xylosidase & 0.12 & 0.78 & n.d. \\
\hline$\alpha$-arabinofuranosidase & 2.35 & 0.26 & n.d. \\
\hline$\beta$-galactosidase & 0.12 & 0.95 & n.d. \\
\hline Laccase & 5.82 & 4.43 & n.d. \\
\hline
\end{tabular}

n.d., not detected.

The noticeable presence of hemicellulases in the $C C$ and $B L$ cocktails is a desirable result, because this group of enzymes promotes hydrolysis of the remaining hemicellulosic fraction after biomass pretreatment, making cellulose more available to the action of cellulases [13,24,25]. Because lignin is usually related to low efficiency in the hydrolysis step [26,27], the laccase present in both extracts is another important characteristic in comparison to the commercial cocktail. Laccase enzyme aids in the removal of residual lignin from biomass and also oxidize phenolic compounds that inhibit cellulases [10,28]. In addition to enzyme variety, the $B L$ presented the highest enzymatic activities, including $\beta$-glucosidase and $\beta$-xylosidase. These enzymes are crucial to a good saccharification yield, because they prevent the accumulation of oligosaccharides, being responsible for the last step of glucose and xylose production, respectively [10]. Thereby, sugarcane bagasse hydrolysis with BL may not be inhibited by cello-oligosaccharides produced by $\beta$-cellobiohydrolase, also presents in this mixture. 
The results of the compositional analysis of raw and pretreated biomass, and the yield of each applied method are presented in Table 3. The severity factor resulting from a specific pretreatment method is related to the percentage of biomass loss which interferes with the efficiency and general costs of the biofuel production process $[10,28]$. The lower yield presented by the dilute acid pretreatment proved the highest severity of this method which resulted in $25.8 \%$ of biomass loss while only $5.9 \%$ and $8.6 \%$ of biomass was lost after hydrothermal pretreatment for 20 and $60 \mathrm{~min}$, respectively. Furthermore, approximately $16 \%$ of the cellulose and lignin contents were solubilized after chemical pretreatment (2-3 times greater than in other methods). Reduction of the hemicellulose concentration ( $47.8 \%$ recovery) in sugarcane bagasse after dilute acid pretreatment was expected, because this method promotes solubilization of the hemicellulosic fraction [29-31], making cellulose more available to the action of enzymes [6]. Despite significant changes in its chemical composition, the AC-SCB presented the largest amount of cellulose and lignin when compared with hydrothermal-pretreated SCB (Table 3).

Table 3. Compositional and mass loss analysis of raw and pretreated sugarcane bagasse. The amounts of cellulose, hemicellulose and lignin are based on the dry weight. Averages in the same column and followed by the same letter do not differ by the Tukey test at $5 \%$ of significance.

\begin{tabular}{lcccc}
\hline \multirow{2}{*}{ Sample } & \multicolumn{3}{c}{ Composition (\%) } & \multirow{2}{*}{ Yield (\%) } \\
\cline { 2 - 4 } & Cellulose & Hemicellulose & Lignin & \\
\hline SCB & $41.25 \pm 0.18^{a}$ & $27.62 \pm 0.50^{a}$ & $23.91 \pm 0.07^{a}$ & 100.00 \\
AC-SCB & $46.76 \pm 0.42^{b}$ & $17.82 \pm 0.26^{b}$ & $26.95 \pm 0.31^{b}$ & 74.19 \\
H20-SCB & $41.62 \pm 0.11^{a}$ & $28.28 \pm 0.47^{a c}$ & $24.58 \pm 0.27^{c}$ & 93.24 \\
H60-SCB & $41.72 \pm 0.23^{a}$ & $29.12 \pm 0.32^{c}$ & $24.12 \pm 0.14^{a c}$ & 90.34 \\
\hline
\end{tabular}

SCB: raw sugarcane bagasse; AC-SCB: acid pretreated sugarcane bagasse; H20-SCB and H60-SCB: hydrothermal pretreated sugarcane bagasse for $20 \mathrm{~min}$ and $60 \mathrm{~min}$, respectively. Hemicellulose: xylan, acetyl and arabinan fractions.

The hydrothermal pretreatment can infiltrate the biomass and moisturize cellulose. This enhance its accessible and susceptible surface area, and improve its accessibility to the hydrolytic enzymes, consequently facilitating the removal of hemicellulose and lignin [32]. Liquid hot water (LHW) is a type of hydrothermal pretreatment that improves enzymatic hydrolysis of cellulose by solubilizing xylan, increasing porosity and decreasing particle size [27,33]. Hydrothermal pretreatment was less effective, even when prolonged, for altering the sugarcane bagasse composition if compared to the use of diluted acid, especially regarding the hemicellulose content since $94.4 \%$ and $95.2 \%$ of this component was recovered in $\mathrm{H} 20$-SCB and H60-SCB, respectively. This is because efficient degradation of hemicellulose under neutral or hydrothermal conditions requires higher temperatures than those required in chemical treatments with acids and alkalis [34]. The temperature applied was $121^{\circ} \mathrm{C}$, but water must reach a minimum of $180^{\circ} \mathrm{C}$ for solubilization of the hemicellulosic fraction to be efficient [34]. Although the solubilization of lignin promoted by the two hydrothermal pretreatments also was slight (more than 90\% recovery), H20-SCB and H60-SCB showed a lignin content lower than AC-SCB (Table 3).

Due to the slight alteration of the biomass composition promoted by the hydrothermal pretreatment, the unpretreated and pretreated samples of sugarcane bagasse were submitted to scanning electron microscopy to evaluate possible structural changes (Figure 1). SCB presented an organized structure, characterized by a smooth and uniform surface, composed of lignocellulosic fibers spliced (Figure $1 \mathrm{~A}$ ). In contrast, the samples resulting from acid and hydrothermal pretreatments (Figures $1 \mathrm{~B}, \mathrm{C}, \mathrm{D}$ ) showed lignocellulosic fibers broken and with more space between them, which indicates greater porosity in pretreated materials. Consequently, the AC-SCB (Figure 1 B), H20-SCB (Figure 1 C) and H60-SCB (Figure 1 D) presented many layers and they were characterized by a high level of disorganization.

Considering that the production of the inhibitors depends on the pretreatment type and that the efficiency of the enzymes in the hydrolysis stage is related to the concentration of degradation compounds in pretreated biomass $[20,35,36]$, the release of inhibitors and their removal by washing were also investigated by each method of pretreatment method employed and the results are shown in Table 4 . The use of dilute acid generated more inhibitors, mainly acetic acid $\left(3.8 \mathrm{~g} \cdot \mathrm{L}^{-1}\right)$ when compared to the use of only water to disrupt the lignocellulosic biomass. Furthermore, the presence of HMF was only observed in the liquor resulted from acid pretreatment. On the other hand, the inhibitor production profile for both hydrothermal pretreatments was similar.

During the biomass pretreatment, the different carbohydrates present in lignocellulosic material can be transformed into many by-products. Cellulose can be converted into oligomers and free glucose or degraded 
into furfural and HMF, while hemicellulose can be converted into pentose and hexose sugars or degraded into aliphatic acids (primarily acetic acid, formic acid and levulinic acid) and furan aldehydes [9,35]. In contrast, the degradation of lignin during the biomass pretreatment results in the release of phenolic compounds [35]. Therefore, these results are in agreement with the data of mass loss and chemical composition changes (Table 3), which were more significant in AC-SCB and slighter and similar for H20-SCB and H60-SCB.
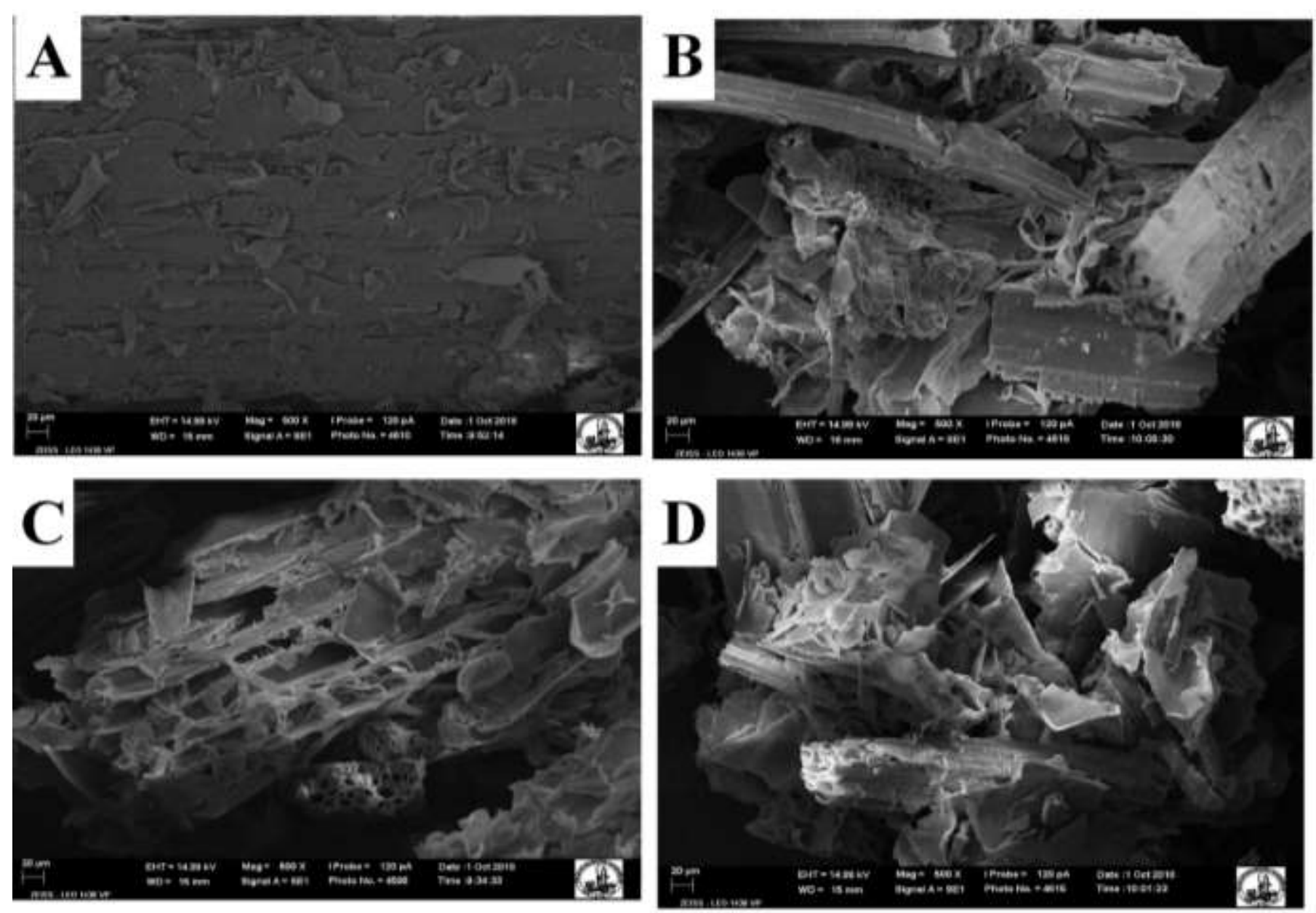

Figure 1. Scanning electron microscopy images of the sugarcane bagasse submitted to different pretreatments methods. Pretreatment abbreviations: no pretreatment $(A)$, acid $(B)$, hydrothermal for 20 min $(C)$ and hydrothermal for $60 \min (D)$.

The concentration for each group of inhibitors presents in liquid fractions obtained after the filtration and first wash of pretreated SCB samples proved that most of all by-products generated in each pretreatment $(54-100 \%)$ were not retained in the solid fraction. Besides, the sole wash performed on the pretreated SCB samples was essential and sufficient to remove all (100\%) or most of the inhibitors that were adhered to the solid fraction (55-75\%). The filtration combined with one wash step was able to eliminate $85-100 \%$ of the undesirable compounds (Table 4).

A previous work [37] evaluated the effects of different cellulase inhibitors in enzymatic saccharification and reported that the efficiency of glucan conversion was decreased only when the concentrations (in $\mathrm{g} \cdot \mathrm{L}^{-1}$ ) of acetic acid, HMF, furfural, formic acid and tannic acid (phenol) were 6.4, 0.3, 3.3, 2.4 and 4, respectively. In addition, another previous study [38] showed that $1 \mathrm{~g} . \mathrm{L}^{-1}$ of phenolic compounds, $3.3 \mathrm{~g} \cdot \mathrm{L}^{-1}$ of acetic acid and $0.6 \mathrm{~g} \cdot \mathrm{L}^{-1}$ of furfural decreased the glucose consumption by $35 \%, 20 \%$ and $15 \%$, respectively, in acetonebutanol-ethanol fermentation, while $0.3 \mathrm{~g} \cdot \mathrm{L}^{-1}$ of levulinic acid and $0.2 \mathrm{~g} . \mathrm{L}^{-1}$ of HMF did not affect the process.

Since the concentration of inhibitors detected after the second wash corresponds to those that remained in the biomass samples used in the saccharification experiments (Table 4), it is possible to affirm that neither as pretreatment slurries much less as AC-SCB, H20-SCB and H60-SCB contained enough inhibitors to impair the enzymatic saccharification and/or the fermentation process. The low concentrations of released inhibitors are due to the mild conditions of pretreatments performed in this study. 
Table 4. Release of inhibitors for each type of pretreatment applied to sugarcane bagasse.

\begin{tabular}{|c|c|c|c|c|c|c|}
\hline \multirow[b]{2}{*}{ Liquid Fraction } & \multicolumn{6}{|c|}{ Inhibitors released $\left(\mathrm{g} \cdot \mathrm{L}^{-1}\right)$} \\
\hline & Phenols & $\begin{array}{c}\text { Acetic } \\
\text { acid }\end{array}$ & Formic acid & Levulinic acid & Furfural & HMF \\
\hline \multicolumn{7}{|l|}{ AC-PT } \\
\hline After filtration & 0.030 & 2.149 & n.d. & n.d. & n.d. & 0.024 \\
\hline After 1st wash & 0.015 & 1.175 & n.d. & n.d. & n.d. & n.d. \\
\hline After 2nd wash & 0.005 & 0.557 & n.d. & n.d. & n.d. & n.d. \\
\hline Total & 0.050 & 3.881 & n.d. & n.d. & n.d. & 0.024 \\
\hline \multicolumn{7}{|l|}{ H20-PT } \\
\hline After filtration & 0.015 & 0.065 & 0.201 & n.d. & n.d. & n.d. \\
\hline After 1st wash & 0.004 & 0.035 & 0.171 & n.d. & n.d. & n.d. \\
\hline After 2nd wash & 0.002 & n.d. & n.d. & n.d. & n.d. & n.d. \\
\hline Total & 0.021 & 0.100 & 0.372 & n.d. & n.d. & n.d. \\
\hline \multicolumn{7}{|l|}{ H60-PT } \\
\hline After filtration & 0.020 & 0.083 & 0.250 & n.d. & n.d. & n.d. \\
\hline After 1st wash & 0.005 & 0.033 & 0.188 & n.d. & n.d. & n.d. \\
\hline After 2nd wash & 0.004 & n.d. & n.d. & n.d. & n.d. & n.d. \\
\hline Total & 0.029 & 0.116 & 0.438 & n.d. & n.d. & n.d. \\
\hline
\end{tabular}

AC-PT: acid pretreatment; H20-PT: hydrothermal pretreatment for 20 min; H60-PT: hydrothermal pretreatment for 60 min; HMF: hydroxymethyl; n.d.: not detected. The values are the average of three repetitions and standard deviations did not exceed $5 \%$ of the mean.

After the enzymatic profiles analysis of the non-commercial and commercial cocktails, evaluation of the effects of the pretreatment on the composition and structure of the SCB and quantification of the generated inhibitors, the saccharification experiments were finally carried out and the results of the glucose and xylose production are shown in Figure 2. A smaller concentration of hemicellulose (Table 3) and the evident structural disorganization (Figure $1 \mathrm{~B}$ ) resulting from the pretreatment stage were not enough to ensure high efficiency in AC-SCB hydrolysis, mainly by MCL (Figures $2 \mathrm{~A}, 3 \mathrm{~A}$ ). The use of acid has considerable disadvantages, such as the increased generation of compounds (furfural and furfural hydroxymethyl) which inhibit the sugar fermentation and may also reduce the activity of some cellulolytic enzymes $[7,11,12]$. The quantity, distribution and toxicity of inhibitor compounds depend, among other factors, on the type and severity of pretreatment [39]. A previous study [10] showed that enzymes of the commercial cocktail Multifect ${ }^{\circledR}$ CL were more efficient than Chrysoporthe cubensis enzymes to convert cellulose from sugarcane bagasse pretreated with $1 \%$ sulfuric acid. However, the same performance was not observed in the present work (Figures $2 \mathrm{~A}, 3 \mathrm{~A}$ ), probably due to the low severity of the acid pretreatment. Pretreatment severity is directly proportional to the concentration of $\mathrm{H}^{+}$protons [40] and the concentration of liberated inhibitor compounds. The greater severity employed in the work aforementioned resulted in biomass with a lower hemicellulose quantity (8.69\%) if compared to the AC-SCB (Table 3), and likely higher inhibitors release. Despite the pretreatment with $0.5 \%$ sulfuric acid had not generated enough inhibitors to impair the enzyme action (Table 4 ), it resulted in a greater need for hemicellulases because the use of cocktails with a greater variety and quantity of these enzymes (BL and $C C$ ) was more advantageous than MCL for AC-SCB saccharification (Figures $2 \mathrm{~A}, 3 \mathrm{~A}$ ). So, the residual hemicellulosic fraction of $\mathrm{AC}-\mathrm{SCB}$ was responsible for the great difference in saccharification efficiency of different extracts tested.

Residual lignin from pretreated biomass hinders hydrolysis by physically blocking access of the enzymes to polysaccharides and non-productively binding enzymes [41]. A higher concentration of lignin was found in the AC-SCB (Table 3). The presence of laccase in the cocktails produced at the laboratory bench level may have contributed positively to the velocity of product formation, minimizing the effects of lignin on the enzymes, because laccase assists in the biomass delignification process [27]. Previous studies have proven that the use of nonionic surfactants (e.g. Tween 20 and 80), polymers (e.g. Polyethylene Glycol - PEG) and non-catalytic protein (e.g. BSA) are some of the alternatives to reduce non-productive binding between enzymes and residual lignin. These compounds enhance the saccharification efficiency because they bind to lignin, allowing the enzymes to remain free to bind to their substrates, such as cellulose and hemicellulose [42-46]. Wang and coauthors [47] observed an improvement in filter paper hydrolysis as well as increased stability of the enzymes and xylan conversion when BSA was added to the reaction medium. Therefore, the best performance of CC in the hydrolysis of hemicellulosic fraction present in AC-SCB (Figures $2 \mathrm{~A}, 3 \mathrm{~A}$ ) is probably due to its high protein concentration, about 3-fold greater than that of BL. Thus, the possible lignin 
blockade caused by CC proteins compensates for the lower activities of cellulases and hemicellulases in this cocktail.
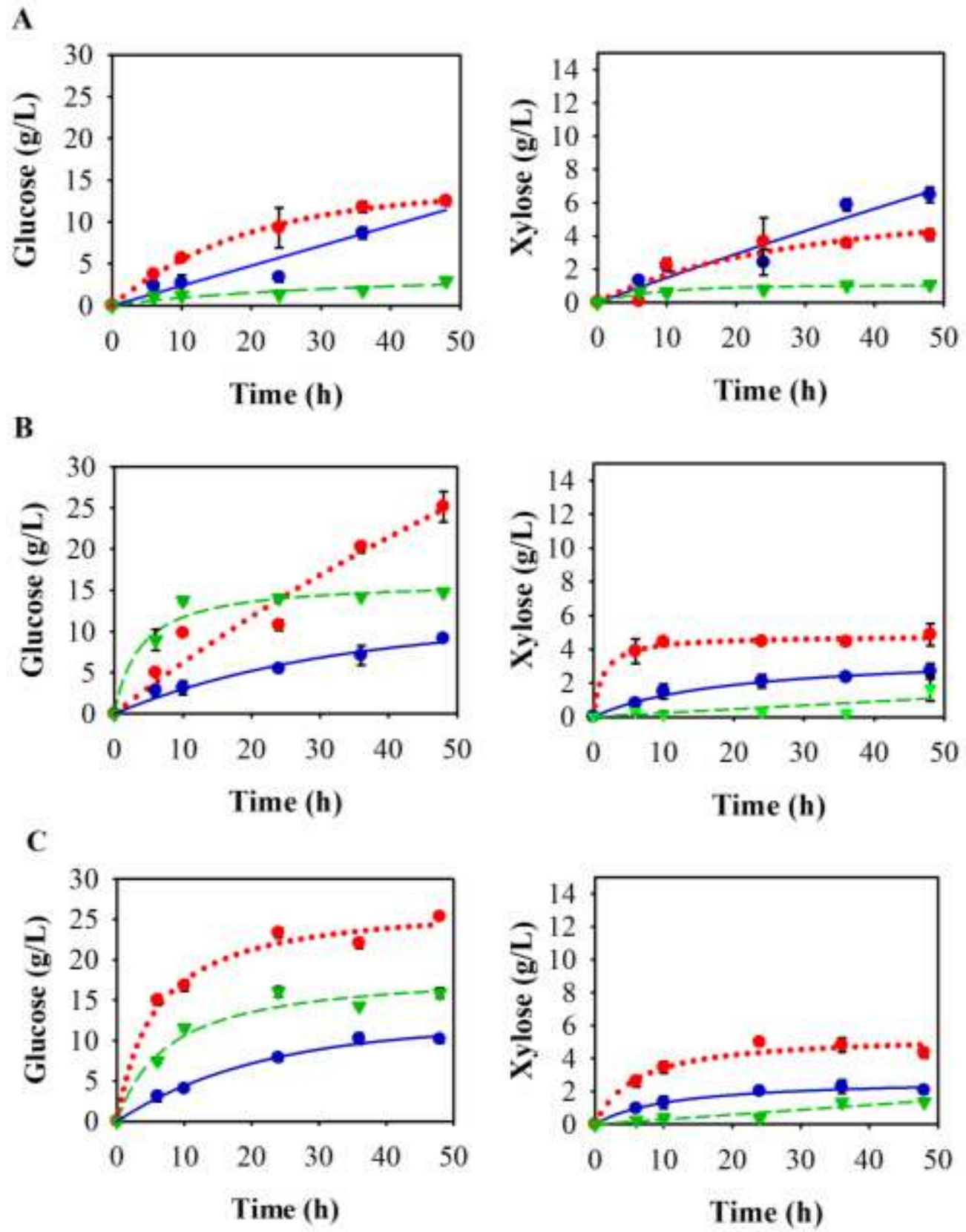

Figure 2. Concentrations of glucose and xylose over $48 \mathrm{~h}$ of sugarcane bagasse saccharification. Pretreatments: acid (A), hydrothermal for $20 \mathrm{~min}$ (B) and hydrothermal for $60 \mathrm{~min}$ (C). Enzymes: Chrysoporthe cubensis crude extract (blue), Chrysoporthe cubensis-Penicillium pinophilum enzyme blend (red) and commercial cocktail Multifect ${ }^{\circledR} \mathrm{CL}$ (green).

Although the temperature used in hydrothermal pretreatment does not allow efficient solubilization of the hemicellulosic fraction (Table 3), the method applied modified the biomass structure, disorganizing its fibers and increasing its porosity (Figure 1) without releasing too many inhibitors (Table 4). Thus, the hydrothermal pretreatment provided excellent results such as an increase in the glucan conversion rate by the MCL cocktail, which surpassed that of CC under this condition (Figures $3 \mathrm{~B}, \mathrm{C}$ ). However, hydrothermal pretreatment decreased the efficiency of xylan hydrolysis by all cocktails if compared to acid pretreatment (Figure 3). These results suggest that the use of hot water improves cellulases action due to the change in the structure of SCB. Furthermore, this method decreased the requirement for hemicellulases to achieve satisfactory glucan conversion rates, since the predominantly cellulase commercial cocktail performed better than $\mathrm{CC}$ in this condition.

De Andrade and coauthors [49] demonstrated the importance of $\beta$-glycosidase in the saccharification of sugarcane bagasse through the supplementation of Multifect ${ }^{\circledR} \mathrm{CL}$ and the $C$. cubensis crude extract with 
different $\beta$-glucosidases, because this enzyme was responsible for increasing the glucan conversion by more than $50 \%$ in alkali-pretreated sugarcane bagasse. Thus, the higher ratio between $\beta$-glucosidase and FPase activities in the BL (Table 2) may justify its excellent performance in the hydrolysis of sugarcane bagasse submitted to hydrothermal pretreatment.
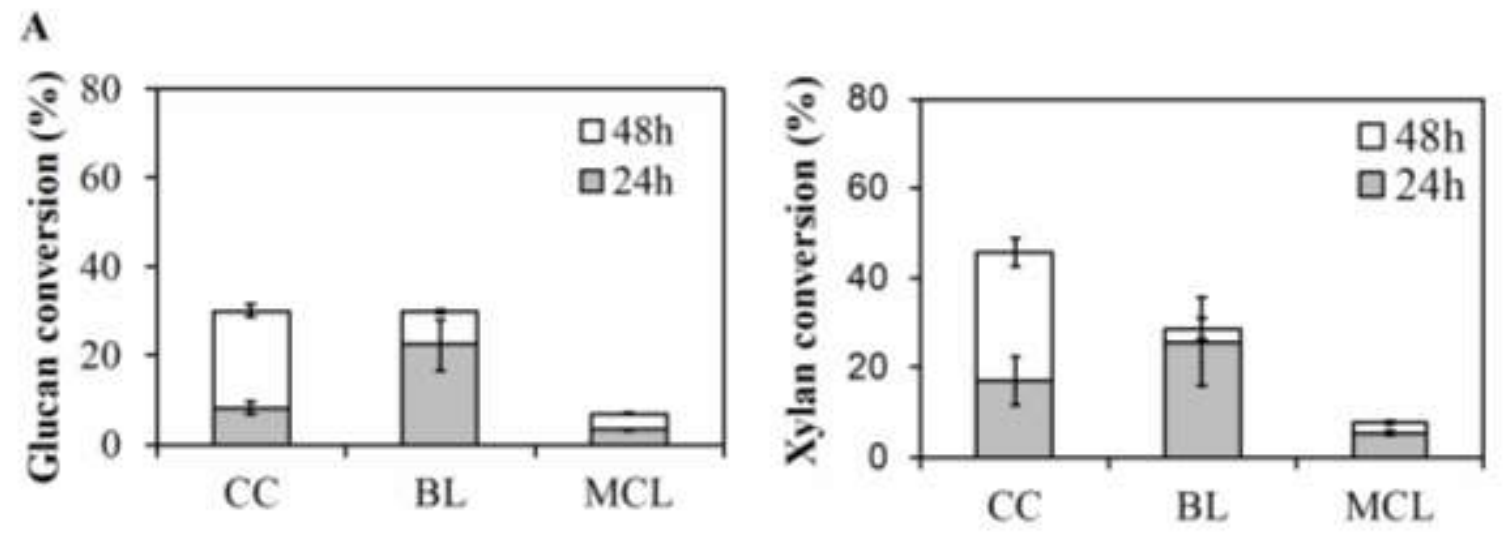

B
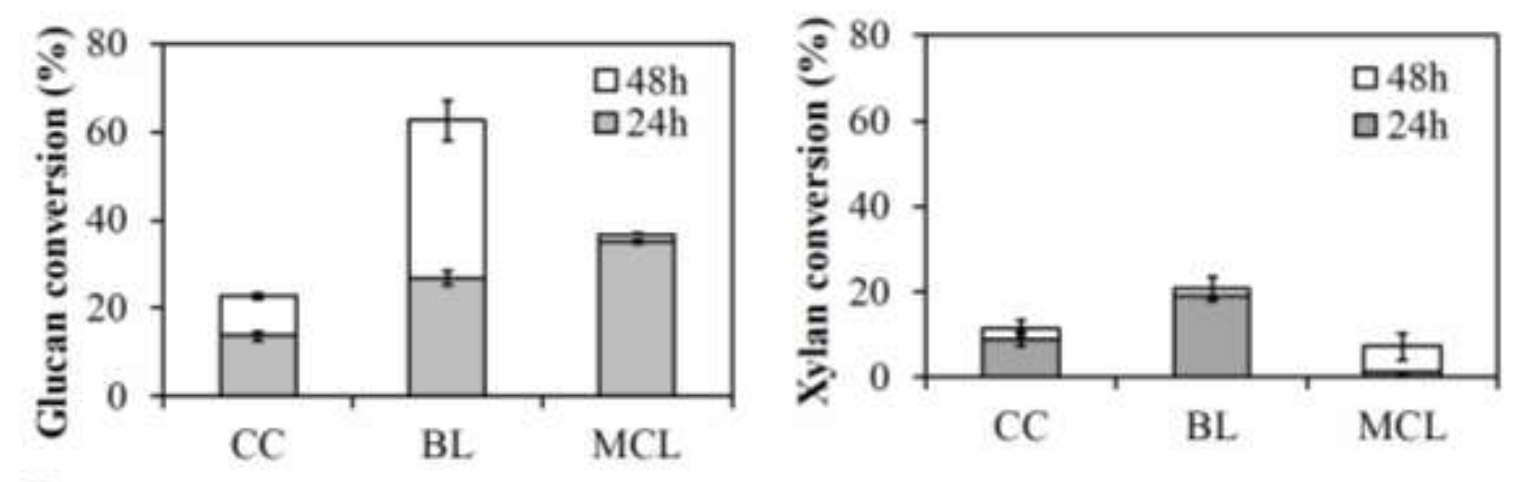

C
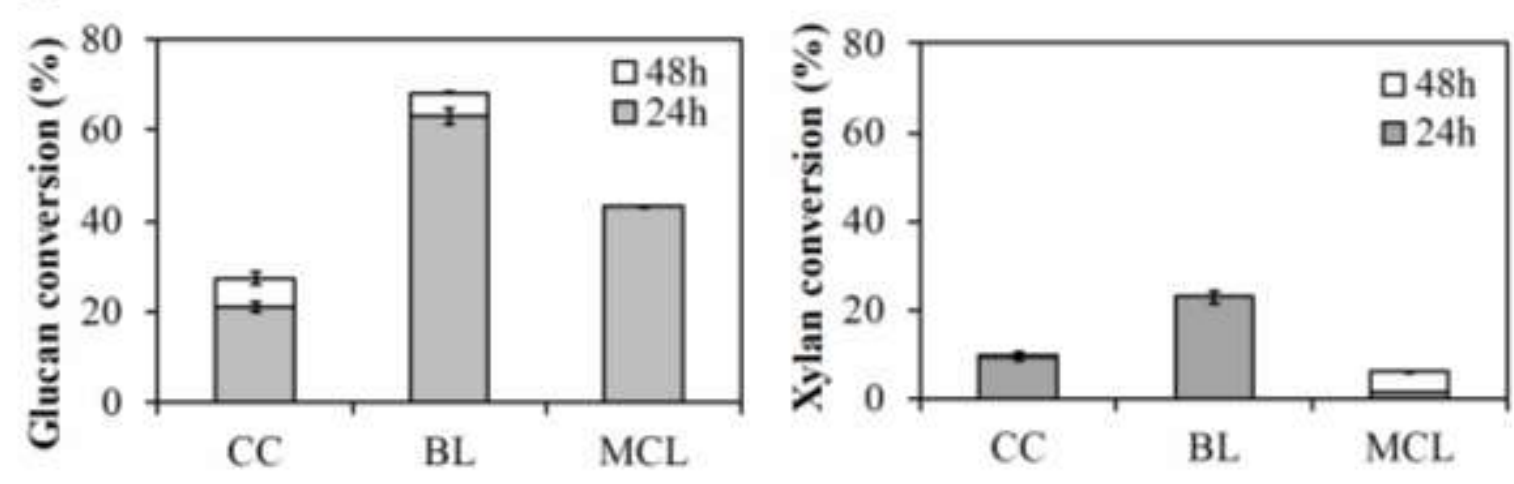

Figure 3. Conversion efficiency of glucan and xylan from sugarcane bagasse every $24 \mathrm{~h}$ of hydrolysis. Enzyme cocktails abbreviations: Chrysoporthe cubensis crude extract (CC), Chrysoporthe cubensis-Penicillium pinophilum enzyme blend $(\mathrm{BL})$ and commercial cocktail Multifect ${ }^{\circledR} \mathrm{CL}(\mathrm{MCL})$. Pretreatments: acid $(\mathrm{A})$, hydrothermal for $20 \mathrm{~min}(\mathrm{~B})$ and hydrothermal for $60 \mathrm{~min}(\mathrm{C})$.

As important as the final sugar concentration and the process yield, is the velocity of glucose and xylose release because a faster process means reduced costs. Visser and coauthors [16] observed excellent sugar yield (60\% of glucose conversion and $90 \%$ of xylose conversion) after 72 hours of sugarcane bagasse hydrolysis with a C.cubensis-P.pinophilum cocktail, but using alkali pretreatment and higher enzymatic load (20 FPU/g of biomass). In the present work, the glucan conversion rates exceeded $60 \%$ after 48 hours of hydrothermal-pretreated SCB saccharification, using only $8 \mathrm{FPU} / \mathrm{g}$ of biomass. These results suggest that hot water pretreatment improves the action of enzymes in the $\mathrm{BL}$, and consequently decreases the amount of enzymes required in the process (Figures $3 \mathrm{~B}, \mathrm{C}$ ).

Most of the pretreatment methods increase the surface area accessible to cellulases through changes in the chemical composition, porosity and structure of the plant biomass [50,51]. Kim and coauthors [34] observed that the increase in residence time of hardwood pretreatment with LHW resulted in an increase of 
$6 \%$ in glucose production. However, though the increase in residence time of the hydrothermal pretreatment has resulted in completely different yields in the first 24 hours of glucan conversion, the total efficiencies of H20-SCB and H60-SCB hydrolysis by the same cocktail were very similar (Figures $3 \mathrm{~B}, \mathrm{C}$ ). These results prove that the increased severity of hydrothermal pretreatment accelerated the action of cellulases in $\mathrm{H60}$ $\mathrm{SCB}$, indicating that the higher rate of glucose formation is due to an increase in pore volume and size, and also the reduction of cellulose crystallinity [50,51], since the chemical compositions of H2O-SCB and H60SCB were very similar (Table 3 ).

Concerning the saccharification time, Maitan-Alfenas and coauthors [10] observed that the crude $C$. cubensis extract hydrolyzed $12.5 \%$ and $7.7 \%$ of the glucan present in alkali and acid pretreated sugarcane bagasse, respectively, after 72 hours. The efficiencies of glucan hydrolysis by CC related here, when acting in different tested substrates, were much higher if compared to the results of the previous work. This result proves that the pretreatment type as well as its severity influence the process and can allow the reduction of saccharification time.

\section{CONCLUSIONS}

The hydrothermal pretreatment, even in mild temperature conditions, is an environmentally correct alternative with the potential to increase the competitiveness of second-generation ethanol. The utilization of this method resulted in satisfactory rates of cellulose conversion in short periods, with lower enzymatic loads and reduced demand for hemicellulases, especially when combined with the use of an enzymatic blend of $C$. cubensis and $P$. pinophilum fungi.

Funding: This research was funded by CAPES, FAPEMIG, and CNPq.

Acknowledgments: We acknowledge the Brazilian institutions Coordenação de Aperfeiçoamento Pessoal de Nível Superior (CAPES) for the scholarship granted to the first author, Fundação de Amparo à Pesquisa de Minas Gerais (FAPEMIG) and Conselho Nacional de Desenvolvimento Científico e Tecnológico (CNPq) for the resources provided to complete this experiment, and also the Nucleus of Microscopy and Microanalysis at the Universidade Federal de Viçosa, (http://www.nmm.ufv.br/) for providing the equipment and technical support for experiments involving electron microscopy.

Conflicts of Interest: The authors declare no conflict of interest.

\section{REFERENCES}

1. Conselho Nacional de Abastecimento. [Monitoring of the Brazilian sugarcane harvest] [Internet]. Brasília (DF): Conab; 2017 Aug. 73 p. Available from: https://www.conab.gov.br/info-agro/safras/cana/boletim-da-safra-de-canade-acucar.

2. Lima MA, Gomez LD, Steele-King CG, Simister R, Bernardinelli OD, Carvalho MA, et al. Evaluating the composition and processing potential of novel sources of Brazilian biomass for sustainable biorenewables production. Biotechnol Biofuels. 2014;7(1):10.

3. Jardine JG, Dispato I, Peres MR. [Considerations on Lignocellulosic Bioethanol to Support the Content Development of the Agroenergy Knowledge Tree] [Internet]. 1st ed. Campinas (SP): Embrapa Informática Agropecuária; $\quad 2009 \quad$ Nov. 28 p. 28 Available from: https://ainfo.cnptia.embrapa.br/digital/bitstream/item/17345/1/doc95.pdf conteudo-da-arvore-do-conhecimentoagroenergia

4. Visser EM, Ferreira TF, De Almeida MN, Guimarães VM. Increased enzymatic hydrolysis of sugarcane bagasse from enzyme recycling. Biotechnol Biofuels. 2015;8(5):1-9.

5. Maitan-Alfenas GP, Visser EM, Guimarães VM. Enzymatic hydrolysis of lignocellulosic biomass: Converting food waste in valuable products. Curr Opin Food Sci. 2015;1:44-9.

6. Silveira MHL, Morais ARC, Lopes AM da C, Olekszyszen DN, Bogel-Łukasik R, Andreaus J, et al. Current Pretreatment Technologies for the Development of Cellulosic Ethanol and Biorefineries. ChemSusChem Rev. 2015;8(20):3366-90.

7. Kumar AK, Sharma S. Recent updates on different methods of pretreatment of lignocellulosic feedstocks: a review. Bioresour Bioprocess. 2017;4(7):1-19.

8. Njoku SI, Ahring BK, Uellendahl H. Pretreatment as the crucial step for a cellulosic ethanol biorefinery: Testing the efficiency of wet explosion on different types of biomass. Bioresour Technol. 2012;124:105-10.

9. Petersen MØ, Larsen J, Thomsen MH. Optimization of hydrothermal pretreatment of wheat straw for production of bioethanol at low water consumption without addition of chemicals. Biomass and Bioenergy. 2009;33:834-40.

10. Maitan-Alfenas GP, Visser EM, Alfenas RF, Nogueira BRG, de Campos GG, Milagres AF, et al. The influence of pretreatment methods on saccharification of sugarcane bagasse by an enzyme extract from Chrysoporthe cubensis and commercial cocktails: A comparative study. Bioresour Technol. 2015;192:670-6.

11. Alvira P, Tomás-Pejó E, Ballesteros M, Negro MJ. Pretreatment technologies for an efficient bioethanol production process based on enzymatic hydrolysis: A review. Bioresour Technol. 2010;101(13):4851-61. 
12. Canilha L, Chandel AK, Milessi TSDS, Antunes FAF, Freitas WLDC, Felipe MDGA, et al. Bioconversion of sugarcane biomass into ethanol: An overview about composition, pretreatment methods, detoxification of hydrolysates, enzymatic saccharification, and ethanol fermentation. J Biomed Biotechnol. 2012;2012:1-15.

13. Falkoski DL, Guimarães VM, de Almeida MN, Alfenas AC, Colodette JL, de Rezende ST. Chrysoporthe cubensis: a new source of cellulases and hemicellulases to application in biomass saccharification processes. Bioresour Technol. 2013;130:296-305.

14. Gao D, Uppugundla N, Chundawat SPS, Yu X, Hermanson S, Gowda K, et al. Hemicellulases and auxiliary enzymes for improved conversion of lignocellulosic biomass to monosaccharides. Biotechnol Biofuels. 2011;4(5):1-11.

15. Dutra TR, Guimarães VM, Varela EM, Fialho L da S, Milagres AMF, Falkoski DL, et al. A Chrysoporthe cubensis enzyme cocktail produced from a low-cost carbon source with high biomass hydrolysis efficiency. Sci Rep. 2017;7(3893):1-9.

16. Visser EM, Falkoski DL, de Almeida MN, Maitan-Alfenas GP, Guimarães VM. Production and application of an enzyme blend from Chrysoporthe cubensis and Penicillium pinophilum with potential for hydrolysis of sugarcane bagasse. Bioresour Technol. 2013;144:587-94.

17. Ghose TK. Measurement of cellulase activities. Pure Appl Chem. 1987;59(2):257-68.

18. Miller GL. Use of dinitrosalicyclic reagent for determination of reducing sugar. Anal Chem. 1959;31:426-8.

19. Bradford M. A rapid and sensitive method for the quantification of microgram quantities of protein utilizing the principle of protein- dye binding. Anal Biochem. 1976;72:248-54.

20. Ladeira-Ázar RIS, Morgan T, Maitan-Alfenas GP, Guimarães VM. Inhibitors Compounds on Sugarcane Bagasse Saccharification: Effects of Pretreatment Methods and Alternatives to Decrease Inhibition. Appl Biochem Biotechnol. 2019;188(1):29-42.

21. Budini R, Tonelli D, Girotti S. Analysis of Total Phenols Using the Prussian Blue Method. J Agric Food Chem. 1980;28(6):1236-8.

22. TAPPI - Technical Association of the Pulp and Paper Industry. Tappi Standard Methods (T-222 om-98). Atlanta; 1999. $14 \mathrm{p}$.

23. Singhania RR, Sukumaran RK, Patel AK, Larroche C, Pandey A. Advancement and comparative profiles in the production technologies using solid-state and submerged fermentation for microbial cellulases. Enzyme Microb Technol. 2010;46(7):541-9.

24. Berlin A, Maximenko V, Gilkes N, Saddler J. Optimization of enzyme complexes for lignocellulose hydrolysis. Biotechnol Bioeng. 2007;97(2):287-96.

25. Juhász T, Szengyel Z, Réczey K, Siika-Aho M, Viikari L. Characterization of cellulases and hemicellulases produced by Trichoderma reesei on various carbon sources. Process Biochem. 2005;40(11):3519-25.

26. Vasconcellos VM, Tardioli PW, Giordano RLC, Farinas CS. Addition of metal ions to a (hemi)cellulolytic enzymatic cocktail produced in-house improves its activity, thermostability, and efficiency in the saccharification of pretreated sugarcane bagasse. N Biotechnol. 2016;33(3):331-7.

27. Ko JK, Ximenes E, Kim Y, Ladisch MR. Adsorption of enzyme onto lignins of liquid hot water pretreated hardwoods. Biotechnol Bioeng. 2015;112(3):447-56.

28. Avanthi A, Banerjee R. A strategic laccase mediated lignin degradation of lignocellulosic feedstocks for ethanol production. Ind Crops Prod. 2016;92:174-85.

29. Agbor VB, Cicek N, Sparling R, Berlin A, Levin DB. Biomass pretreatment: Fundamentals toward application. Biotechnol Adv. 2011;29(6):675-85.

30. Kumar P, Barrett DM, Delwiche MJ, Stroeve P. Methods for pretreatment of lignocellulosic biomass for efficient hydrolysis and biofuel production. Ind Eng Chem Res. 2009;48(8):3713-29.

31. Hendriks ATWM, Zeeman G. Pretreatments to enhance the digestibility of lignocellulosic biomass. Bioresour Technol. 2009;100(1):10-8.

32. Badiei M, Asim N, Jahim JM, Sopian K. Comparison of Chemical Pretreatment Methods for Cellulosic Biomass. APCBEE Procedia. 2014;9:170-4.

33. Zaafouri K, Ziadi M, Hassen-Trabelsi A Ben, Mekni S, Aïssi B, Alaya M, et al. Optimization of Hydrothermal and Diluted Acid Pretreatments of Tunisian Luffa cylindrica (L.) Fibers for 2G Bioethanol Production through the Cubic Central Composite Experimental Design CCD: Response Surface Methodology. Biomed Res Int. 2017;2017:1-14.

34. Kim Y, Kreke T, Mosier NS, Ladisch MR. Severity factor coefficients for subcritical liquid hot water pretreatment of hardwood chips. Biotechnol Bioeng. 2014;111(2):254-63.

35. Bobleter O. Hydrothermal degradation of polymers derived from plants. Prog Polym Sci. 1994;19(5):797-841.

36. Jönsson LJ, Alriksson B, Nilvebrant N-O. Bioconversion of lignocellulose: inhibitors and detoxification. Biotechnol Biofuels. 2013;6(16).

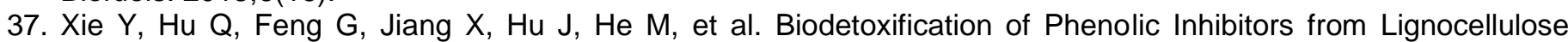
Pretreatment using Kurthia huakuii LAM0618T and Subsequent Lactic Acid Fermentation. Molecules. 2018;23(10):2626.

38. Zakaria MR, Hirata S, Fujimoto S, Ibrahim I, Hassan MA. Soluble inhibitors generated during hydrothermal pretreatment of oil palm mesocarp fiber suppressed the catalytic activity of Acremonium cellulase. Bioresour Technol. 2016;200:541-7. 
39. Paniagua-García Al, Hijosa-Valsero M, Díez-Antolínez R, Sánchez ME, Coca M. Enzymatic hydrolysis and detoxification of lignocellulosic biomass are not always necessary for ABE fermentation: The case of Panicum virgatum. Biomass and Bioenergy. 2018;116:131-9.

40. Kim Y, Ximenes E, Mosier NS, Ladisch MR. Soluble inhibitors/deactivators of cellulase enzymes from lignocellulosic biomass. Enzyme Microb Technol. 2011;48(4-5):408-15.

41. Pedersen M, Meyer AS. Lignocellulose pretreatment severity - relating $\mathrm{pH}$ to biomatrix opening. $\mathrm{N}$ Biotechnol. 2010;27(6):739-50.

42. Kellock M, Rahikainen J, Marjamaa K, Kruus K. Lignin-derived inhibition of monocomponent cellulases and a xylanase in the hydrolysis of lignocellulosics. Bioresour Technol. 2017;232:183-91.

43. Kristensen JB, Börjesson J, Bruun MH, Tjerneld F, Jørgensen $\mathrm{H}$. Use of surface active additives in enzymatic hydrolysis of wheat straw lignocellulose. Enzyme Microb Technol. 2007;40(4):888-895.

44. Banerjee S, Mudliar S, Sen R, Giri B, Satpute D, Chakrabarti T, et al. Commercializing lignocellulosic bioethanol: Technology bottlenecks and possible remedies. Biofuels, Bioprod Biorefining. 2010;4:77-93.

45. Liu H, Sun J, Leu SY, Chen S. Toward a fundamental understanding of cellulase-lignin interactions in the whole slurry enzymatic saccharification process. Biofuels, Bioproducts and Biorefining. 2016;10(5):648-663.

46. Saini JK, Patel AK, Adsul M, Singhania RR. Cellulase adsorption on lignin: A roadblock for economic hydrolysis of biomass. Renew Energy. 2016;98:29-42.

47. Wang $\mathrm{H}$, Kobayashi S, Mochidzuki K. Effect of non-enzymatic proteins on enzymatic hydrolysis and simultaneous saccharification and fermentation of different lignocellulosic materials. Bioresour Technol. 2015;190:373-380.

48. Wang H, Mochidzuki K, Kobayashi S, Hiraide H, Wang X, Cui Z. Effect of bovine serum albumin (BSA) on enzymatic cellulose hydrolysis. Appl Biochem Biotechnol. 2013;170(3):541-51.

49. De Andrade LGA, Maitan-Alfenas GP, Morgan T, Gomes KS, Falkoski DL, Alfenas RF, et al. Sugarcane bagasse saccharification by purified $\beta$-glucosidases from Chrysoporthe cubensis. Biocatal Agric Biotechnol. 2017;12:199205.

50. Liu ZH, Qin L, Li BZ, Yuan YJ. Physical and chemical characterizations of corn stover from leading pretreatment methods and effects on enzymatic hydrolysis. ACS Sustain Chem Eng. 2015;3(1):140-6.

51. Zhao X, Zhang L, Liu D. Biomass recalcitrance. Part I: the chemical compositions and physical structures affecting the enzymatic hydrolysis of lignocellulose. Biofuels, Bioprod Biorefining. 2012;6(4):465-82. 